Article

\title{
New Insight into Antimicrobial Compounds from Food and Marine-Sourced Carnobacterium Species through Phenotype and Genome Analyses
}

\author{
Simon Begrem ${ }^{1,2}$, Flora Ivaniuk ${ }^{2}$, Frédérique Gigout-Chevalier ${ }^{2}$, Laetitia Kolypczuk ${ }^{2}$, \\ Sandrine Bonnetot ${ }^{2}$, Françoise Leroi ${ }^{2}$, Olivier Grovel ${ }^{1} \mathbb{D}$, Christine Delbarre-Ladrat $^{2}{ }^{\mathbb{D}}$ and \\ Delphine Passerini ${ }^{2, *}$ (D) \\ 1 University of Nantes, 44035 Nantes CEDEX 1, France; simon.begrem@etu.univ-nantes.fr (S.B.); \\ olivier.grovel@univ-nantes.fr (O.G.) \\ 2 IFREMER, BRM, EM3B Laboratory, 44300 Nantes CEDEX 3, France; flora.ivaniuk@free.fr (F.I.); \\ frederique.gigout@ifremer.fr (F.G.-C.); Laetitia.Kolypczuk@ifremer.fr (L.K.); \\ Sandrine.Bonnetot@ifremer.fr (S.B.); Francoise.Leroi@ifremer.fr (F.L.); \\ Christine.Delbarre.Ladrat@ifremer.fr (C.D.-L.) \\ * Correspondence: Delphine.Passerini@ifremer.fr
}

Received: 6 July 2020; Accepted: 19 July 2020; Published: 21 July 2020

\begin{abstract}
Carnobacterium maltaromaticum and Carnobacterium divergens, isolated from food products, are lactic acid bacteria known to produce active and efficient bacteriocins. Other species, particularly those originating from marine sources, are less studied. The aim of the study is to select promising strains with antimicrobial potential by combining genomic and phenotypic approaches on large datasets comprising 12 Carnobacterium species. The biosynthetic gene cluster (BGCs) diversity of 39 publicly available Carnobacterium spp. genomes revealed 67 BGCs, distributed according to the species and ecological niches. From zero to six BGCs were predicted per strain and classified into four classes: terpene, NRPS (non-ribosomal peptide synthetase), NRPS-PKS (hybrid non-ribosomal peptide synthetase-polyketide synthase), RiPP (ribosomally synthesized and post-translationally modified peptide). In parallel, the antimicrobial activity of 260 strains from seafood products was evaluated. Among the $60 \%$ of active strains, three genomes were sequenced and submitted to a dereplication process. $C$. inhibens MIP2551 produced a high amountof $\mathrm{H}_{2} \mathrm{O}_{2}$, probably thanks to the presence of four oxidase-encoding genes. C. maltaromaticum EBP3019 and SF668 strains were highly efficient against Listeria monocytogenes. A new extracellular $16 \mathrm{kDa}$ unmodified bacteriocin in the EBP3019 strain and five different bacteriocins in SF668 were highlighted. In this study, the overview of antimicrobial BGC and inhibitory activities of Carnobacterium spp. allowed the prediction of potential innovative natural products that could be relevant for biotechnological applications.
\end{abstract}

Keywords: lactic acid bacteria; antimicrobial activity; Carnobacterium spp.; hydrogen peroxide; bacteriocin; RiPP; NRPS; terpene; natural product; genome mining

\section{Introduction}

Lactic acid bacteria (LAB) are microaerophilic Gram-positive bacteria capable of fermenting sugars into lactic acid. Due to this feature, LAB are involved in various food fermentations such as dairy, meat, or vegetable products. Moreover, they are ubiquitous microorganisms present in many terrestrial environments, ranging from soil, plants, or animals. LAB can also be found in marine environments such as coastal and estuarine sediment or in fish gastrointestinal tract [1]. LAB have developed strategies to outcompete microorganisms in these various ecosystems, such as nutritional competition, environmental acidification, or production of secondary metabolites [2]. 
The production of active secondary metabolites by LAB is well documented. They include end or by-products such as organic acids, diacetyl, and hydrogen peroxide [3], and active peptides named bacteriocins [4-6]. These peptides exhibit antimicrobial activities against Gram-positive bacteria and rarely against Gram-negative bacteria and fungi [7]. Bacteriocin production is strain-dependent, and gene clusters allowing the production of such bacteriocins seem to be subjected to evolutionary selection, favoring the survival of specific bacterial strains in their environment $[8,9]$. Various classifications of bacteriocins have been proposed [10-12]. In this paper, bacteriocins will be designated following the classification of ribosomally synthesized and post-translationally modified peptides (RiPPs) [13]. In contrast to RiPPs, only two active secondary metabolites biosynthesized by a hybrid non-ribosomal peptide synthetase/polyketide synthase (NRPS/PKS) were described in LAB. One of them is involved in oxidative stress resistance [14], and the other inhibits Gram-positive bacteria growth [15].

The production of secondary metabolites can be encoded by different genes co-localized in genetic clusters within the genome called biosynthetic gene clusters (BGCs). Genome mining is a computational analysis approach that allows in silico prediction of BGCs in genomes leading to the identification of novel natural products [16-18]. A wide diversity of natural products encoded by BGCs can, thus be predicted by this approach, e.g., terpenes, RiPP, PKS (synthesized by a polyketide synthase), NRPS (synthesized by a non-ribosomal peptide synthetase), and hybrid NRPS/PKS. The dereplication process consists of the comparison of these predictions with databases to identify original BGCs. Phylogenetically-related organisms isolated from different ecological niches likely exhibit different genetic and phenotypic traits $[19,20]$ and have the potential to biosynthesize various secondary metabolites [21]. In particular, organisms of marine origin are a promising source of innovative secondary metabolites $[22,23]$.

Carnobacterium strains are lactic acid bacteria associated with food products or marine environments [24]. Twelve species have been reported: C. alterfunditum, C. antarcticum, C. divergens, C. funditum, C. gallinarum, C. jeotgali, C. iners, C. inhibens, C. maltaromaticum, C. mobile, C. pleistocenium, and C. viridans. Among them, C. maltaromaticum and C. divergens are frequently isolated from meat and fish products and are used for biopreservation applications [25]. They were shown to prevent Gram-positive bacteria from growing, such as pathogenic (e.g., Listeria monocytogenes) or food-spoiling bacteria, through the production of bacteriocins [24,26,27]. To date, 18 different bacteriocins have been described in Carnobacterium spp., and most of them were produced by C. maltaromaticum and C. divergens strains isolated from food products (Table S1). Among other species, some strains displayed activities against Gram-negative bacteria and fungi, although the mechanisms have not been identified yet $[28,29]$. Moreover, a hybrid NRPS/PKS BGC was predicted in C. divergens V41 strain, but no product or biological activity has been linked to this cluster yet [30].

The aim of this study was to investigate the antimicrobial activities and potential compounds produced by Carnobacterium spp. strains by two complementary approaches. First, the extent of BGCs diversity was evaluated from 89 Carnobacterium spp. publicly available genomes after validation of the species affiliation by phylogenomic analyses. Second, the antimicrobial activity of an unexplored collection of 260 Carnobacterium spp. isolates from seafood products was investigated. The genome of three atypical strains was sequenced and analyzed to highlight genomic specificities, using a dereplication process from genome mining. Besides the overview of BGCs distribution according to Carnobacterium species and their ecological niches, this study allowed the identification of new natural products potentially active.

\section{Materials and Methods}

\subsection{Carnobacterium spp. Public Genome Dataset}

A total of 89 Carnobacterium spp. genomes were collected from the NCBI Assembly database (Table S2). Their 16S rDNA sequences were compared to identify the Carnobacterium species. Sequence alignment was performed with MUSCLE [31] and the maximum likelihood phylogenic tree was 
constructed using MEGA6 [32]. Phylogenetically closely related organisms, namely Aerococcus urinaequii CCUG 28094 (Culture Collection University of Gothenburg, Sweden), Granulicatella adaciens ATCC 49175 (American Type Culture Collection, USA), and Pisciglobus halotolerans DSM 27630 (German Collection of Microorganisms and cell cultures, Germany), were included in the phylogenetic analyses. Lactococcus garvieae ATCC 49156 was used as the outgroup. The OrthoANI-Usearch (OAU) software from EZbiocloud [33] was used to calculate the Average Nucleotide Identity (ANI) between the Carnobacterium spp. strains.

\subsection{EBP3019, SF668, and MIP2551 Genome Sequencing and Automatic Annotation}

One isolated colony was grown in $10 \mathrm{~mL}$ Brain Heart Infusion (BHI, Biokar Diagnostic, Beauvais, France) medium at $26^{\circ} \mathrm{C}$ overnight. Five milliliters were centrifuged, and genomic DNA was extracted using the Wizard Genomic DNA Purification Kit (Promega, Madison, WI, USA). The protocol provided by the supplier was slightly modified with a supplementary prior lysis step as follows: $600 \mu \mathrm{L}$ of Tris buffer containing $1 \mathrm{mM}$ ethylenediaminetetraacetic acid (EDTA) and $10 \mathrm{mg} / \mathrm{mL}$ lysozyme were added and incubated for $1 \mathrm{~h}$ at $37^{\circ} \mathrm{C}$. The DNA was harvested in $25 \mu \mathrm{L}$ of $\mathrm{H}_{2} \mathrm{O}$ and quantified with the NanoVue photometer (VWR, Fontenay-sous-Bois, France). The genomic DNA was sequenced by an Illumina Hi-Seq 2500 system with a read length of $2 \times 250$ bp (Genoscreen, Lille, France). A total of 1,164,664 reads for the MIP2551 strain, 807,963 for the SF668 strain, and 891,855 for the EBP3019 strain were produced. The coverage was over $50 \times$. After quality filtering, de novo assembly was performed with SPAdes v3.8.0 [34]. A total of 42 contigs for the MIP2551 strain, 109 contigs for the EBP3019 strain, and 81 contigs for the SF668 strain were obtained, accounting for a total genomic length of $2.4 \mathrm{Mb}, 3.4 \mathrm{Mb}$, and $3.4 \mathrm{Mb}$, respectively. The automatic annotation was carried out by the MicroScope platform [35].

\subsection{BGC Prediction}

All Carnobacterium spp. genomes were submitted to the RAST ${ }^{\text {nmpdr }}$ (Rapid Annotation using Subsystems technology) [36] and MicroScope platform for automatic annotation [35].

Genes encoding the main enzymes that contribute to $\mathrm{H}_{2} \mathrm{O}_{2}$ accumulation or recycling were identified from the automatic annotation-lactate oxidase (lox, EC.1.13.12.4), pyruvate oxidase (pox, EC.1.2.3.3) [37], $\alpha$-glycerophosphate oxidase (glpO, EC.1.1.3.21) [38], and catalase (EC.1.11.1.6).

BGCs putatively involved in antimicrobial compound biosyntheses were identified by combining the AntiSMASH 5.0 [39] and BAGEL 4 [40] softwares. AntiSMASH is a web-based pipeline able to predict a large diversity of BGCs such as RiPPs, NRPS, PKS, terpenes, and siderophores. BAGEL is specialized in bacteriocin and RiPP cluster prediction. For each predicted BGC class, the presence of a minimal gene subset required for BGCs was investigated as follows. For RiPP clusters, the presence of a structural gene (core gene), an immunity protein-encoding gene, and accessory genes leading to post-translational modifications was investigated. When the core or immunity protein gene was not predicted, it was manually searched using Artemis [41] to predict small coding sequences (CDS). BLASTp was used to compare core sequences, conserved domains, and genetic environments of the Carnobacterium spp. BGCs. The hydrophobicity and high isoelectric point for the predicted head to tail cyclized peptide core sequence were checked according to Gabrielsen et al. with GPMAW lite $[42,43]$. SignalP-5.0 was used to predict extracellular proteins and the cleavage position between the peptide signal and the core peptide [44]. For NRPS/PKS clusters identified by AntiSMASH, the presence of the required initiation and termination modules was checked.

A BGC network was built using the BiG-SCAPE software [45]. This network includes 77 BGCs previously predicted with AntiSMASH and BAGEL. When available, the genetically closest BGCs, already described in the literature were included. The network was built with a local mode and a cutoff parameter of 0.7. The layout of the network was done with BiG-SCAPE for spacing and connections between the different nodes and with Cytoscape for colorization and connector width based on the squared similarity parameter. 


\subsection{Carnobacterium spp. Strains, Growth Conditions, and Identification}

For this study, 260 Carnobacterium spp. strains isolated by Ifremer (Nantes, France) from seafood products (smoked salmon, shrimps, and cod), and 12 reference strains were used (Table S3). Strains were stored at $-80{ }^{\circ} \mathrm{C}$ in $15 \%(\mathrm{v} / \mathrm{v})$ glycerol. Two successive pre-cultures were performed in BHI medium at $26^{\circ} \mathrm{C}$ for $24 \mathrm{~h}$.

Strains were identified using partial 16S rDNA sequencing. Briefly, $500 \mu \mathrm{L}$ of culture suspensions were centrifuged for $20 \mathrm{~min}$ at $4500 \mathrm{~g}$. Pellets were washed twice in $500 \mu \mathrm{L}$ of $10 \mathrm{mM}$ Tris containing $1 \mathrm{mM}$ EDTA and resuspended in $200 \mu \mathrm{L}$ of the same buffer before heating for $10 \mathrm{~min}$ at $95{ }^{\circ} \mathrm{C}$. After centrifugation for $10 \mathrm{~min}$ at $4500 \times g, 1 \mu \mathrm{L}$ of supernatant was used for PCR amplification of the $16 \mathrm{~S}$ rRNA gene using the universal primers, E8-F (5'-AGAGTTTGATCATGGCTCAG-3') and 1489R (5'-GTTACCTTGTTACGACTTCAC-3'). PCR amplification was performed under the following conditions: initial denaturation at $95^{\circ} \mathrm{C}$ for $5 \mathrm{~min} ; 30$ cycles of amplification, including three steps $\left(95{ }^{\circ} \mathrm{C}\right.$ for $30 \mathrm{~s}, 52{ }^{\circ} \mathrm{C}$ for $30 \mathrm{~s}, 72{ }^{\circ} \mathrm{C}$ for $1 \mathrm{~min}$ ), final extension for $10 \mathrm{~min}$ at $72{ }^{\circ} \mathrm{C}$ using a $\mathrm{T} 100^{\mathrm{TM}}$ Thermal Cycler (Bio-Rad, Hercules, CA, USA) in a final volume of $50 \mu \mathrm{L}$. The master mix $1 \mathrm{X}$ with the DreamTaq Green polymerase (Thermo Fisher Scientific, Waltham, MA, USA) was used. PCR products were purified, and the V1-V4 region was sequenced using the E8-F primer (Genoscreen, Lille, France).

\subsection{Spot-On Lawn Assays}

Carnobacterium spp. strains (260 from Ifremer collection and 12 references) were screened for antimicrobial activity by the spot-on lawn method adapted from Matamoros et al. [46]. Seventeen indicator strains involved in human infections, fish diseases, and food spoilage (Table S3) were used: Enterococcus faecalis CIP 105042 (Collection of the Institut Pasteur, France), Staphylococcus epidermidis CIP 68.21, Listeria innocua CIP 107775, Listeria monocytogenes RF191 [47], Vagococcus salmoninarum CIP $104684^{\mathrm{T}}$, Lactococcus garvieae CIP $102507^{\mathrm{T}}$, Carnobacterium divergens V41 [48], Brochothrix thermosphacta CIP $103251^{\mathrm{T}}$, Escherichia coli JM109, Vibrio parahaemolyticus LMG 2850, Pseudomonas fluorescens CIP $69.13^{\mathrm{T}}$, Morganella morganii CIP A231 ${ }^{\mathrm{T}}$, Aeromonas salmonicida CIP $103209^{\mathrm{T}}$, Vibrio harveyi LMG 4044, Chromobacterium violaceum CIP 103350 ${ }^{\mathrm{T}}$, Candida albicans DSM 1386, and Aspergillus fumigatus MMS839 from the MMS laboratory fungal culture collection (Mer Molécules Santé Laboratory, Nantes University, France).

Ten microliters of 24-h culture broth or cell-free supernatants (CFSs) were spotted on the surface of the soft agar medium seeded with one of the bacterial or yeast indicator strains. Indicator bacterial strains were prepared as follows - two successive cultures were performed in $10 \mathrm{~mL}$ appropriate medium at $26^{\circ} \mathrm{C}$ for $24 \mathrm{~h}$. Except for Aeromonas salmonicida, Chromobacterium violaceum, and Pseudomonas fluorescens, which were grown in Tryptic Soy Broth (TSB, Biokar Diagnostic, Beauvais, France), all bacteria grew in BHI medium. Candida albicans was cultured in Lysogeny Broth (LB, 1\% Tryptone; 0.5\% Yeast extract; $1 \% \mathrm{NaCl}$ ). Bacterial indicator strains and Candida albicans were then inoculated in $20 \mathrm{~mL}$ of the culture medium supplemented with $0.5 \%$ agar to reach an initial concentration of $10^{4} \mathrm{CFU} / \mathrm{mL}$ and poured into one square Petri dish $(120 \times 120 \mathrm{~mm})$. A $10^{6}$ spores/mL Aspergillus fumigatus MMS839 suspension was prepared by scraping cells with sterile water from a 96-h culture on Dextrose Casein Agar medium (DCA, Detroit, MI, USA). Three milliliters of spore suspension was left for 5 min on a $0.5 \%$ agar Mueller Hinton Broth (DCA, Detroit, MI, USA) surface in a square Petri dish $(120 \times 120 \mathrm{~mm})$. The excess of liquid was discarded, and then the Carnobacterium spp. cultures were spotted. Clear haloes observed after 24 or $48-\mathrm{h}$ incubation at $26{ }^{\circ} \mathrm{C}$ indicated growth inhibition.

\subsection{Hydrogen Peroxide Quantification}

In order to assess the inhibition caused by the production of hydrogen peroxide $\left(\mathrm{H}_{2} \mathrm{O}_{2}\right)$, antimicrobial assays were performed by adding 5000 Units of bovine liver catalase (Merck, Darmstadt, Germany) in the agar medium. 
Kinetics of $\mathrm{H}_{2} \mathrm{O}_{2}$ production was evaluated for C. inhibens MIP2551 and compared to Lactococcus garvieae CIP $102507^{\mathrm{T}}$. Each strain was grown in Erlenmeyer flasks containing $20 \mathrm{~mL}$ of BHI medium, at $26^{\circ} \mathrm{C}$ under a 150-rpm shaking. The $\mathrm{OD}_{600 \mathrm{~nm}}$ and $\mathrm{H}_{2} \mathrm{O}_{2}$ concentrations were measured at $0,3 \mathrm{~h}, 6 \mathrm{~h}, 9 \mathrm{~h}, 15 \mathrm{~h}$, $18 \mathrm{~h}$, and $24 \mathrm{~h} . \mathrm{H}_{2} \mathrm{O}_{2}$ concentration was estimated using Dosatest@Peroxide test strips 25, 100, and 1000 (VWR, Fontenay-sous-Bois, France).

\subsection{Peptidic Activity of Cell-Free Supernatants (CFSs)}

Carnobacterium spp. cultures were performed in $1 \mathrm{~mL}$ of BHI medium in 96 Deepwell plates for $24 \mathrm{~h}$ at $26^{\circ} \mathrm{C}$. After centrifugation for $30 \mathrm{~min}$ at $5000 \times g, 250 \mu \mathrm{L}$ of supernatants were transferred into the Multiscreen ${ }^{\mathrm{TM}}$ system consisting of a microplate containing $0.22 \mu \mathrm{m}$ polyvinylidene fluoride (PVDF) filters, Merck Millipore, Burlington, NJ, USA), a 96-well microplate receiver (Greiner Bio-One, Grosseron, France), and a Centrifuge Alignment Device (Merck Millipore, Burlington, NJ, USA). After 5 min of centrifugation at $5000 \times g$, cell free supernatants (CFSs) were collected and stored at $-80{ }^{\circ} \mathrm{C}$.

To determine whether the active compounds were peptidic, $100 \mu \mathrm{L}$ CFSs were digested by $1 \mu \mathrm{L}$ of proteinase K (Proteinase K from Engyodontium album EC 3.4.21.64; Merck, Darmstadt, Germany) at a final concentration of $0.2 \mathrm{mg} / \mathrm{mL}$ for $1 \mathrm{~h}$ at $37^{\circ} \mathrm{C}$. The digested CFSs were then spotted on previously inhibited indicator strains seeded in the agar medium, as described above. The absence of inhibition halo after proteinase $\mathrm{K}$ treatment evidenced an active antimicrobial peptide. The efficacy of each CFS was compared using L. monocytogenes RF191 as the indicator strain. Two-fold serial dilutions of CFS suspensions in BHI were inoculated with $10^{6} \mathrm{CFU} / \mathrm{mL}$ of L. monocytogenes RF191 and incubated for $24 \mathrm{~h}$ at $26{ }^{\circ} \mathrm{C}$. The titration of Carnobacterium spp. CFSs was carried out by measuring the growth of L. monocytogenes by $\mathrm{OD}_{600 \mathrm{~nm}}$ with a spectrophotometer (Varioskan ${ }^{\mathrm{TM}}$, Thermo Fisher Scientific, Waltham, MA, USA). A negative control, CFS of Carnobacterium maltaromaticum EBP3034 strain, was included in the analysis. The minimal inhibitory dilution (MID) was determined by the highest dilution of CFS for which no growth of L. monocytogenes was measured.

\subsection{Nucleotide Sequence Accession Number}

The Whole Genome Shotgun projects were deposited in DDBJ/ENA/GenBank under the related accession number WNJQ00000000 for the MIP2551 strain, WNJR00000000 for the SF668 strain, and WNJS00000000 for the EBP3019 strain. The version described in this paper is the first one.

\section{Results}

\subsection{BGC Content Comparison in Carnobacterium Species}

\subsubsection{Carnobacterium spp. Genome Dataset}

Eighty-nine Carnobacterium spp. genome sequences were retrieved from the NCBI database (Table S2). The species affiliation was checked by $16 \mathrm{~S}$ rDNA-based phylogeny (Figure S1) and by phylogenomics using the ANI (Average Nucleotide Identity) similarity values (Figure 1). Whereas the analysis by $16 \mathrm{~S}$ rDNA-based phylogeny alone was sufficient for most species' affiliation, in accordance with the current classification with a high threshold of $99 \%$, the phylogenomics one was required to distinguish the species C. alterfunditum and C. pleistocenium. The Carnobacterium sp. AT7 strain was, thus identified as C. jeotgali, and the WN1374 and 17-4 strains as C. viridans species. This analysis also detected three erroneously identified Carnobacterium sp.- - the strain ZWU0011 was identified in this study as Pisciglobus halotolerans, the strain 757_CMAL as Granulicatella adaciens, and the strain 1290_CSPC as Aerococcus urinaequii (Figure 1 and Figure S1). Consequently, these three strains were excluded from our dataset. To simplify further analysis, redundant genomes were also removed. Finally, 39 Carnobacterium spp. genomes were selected from the dataset to mine Carnobacterium spp. BGCs. 


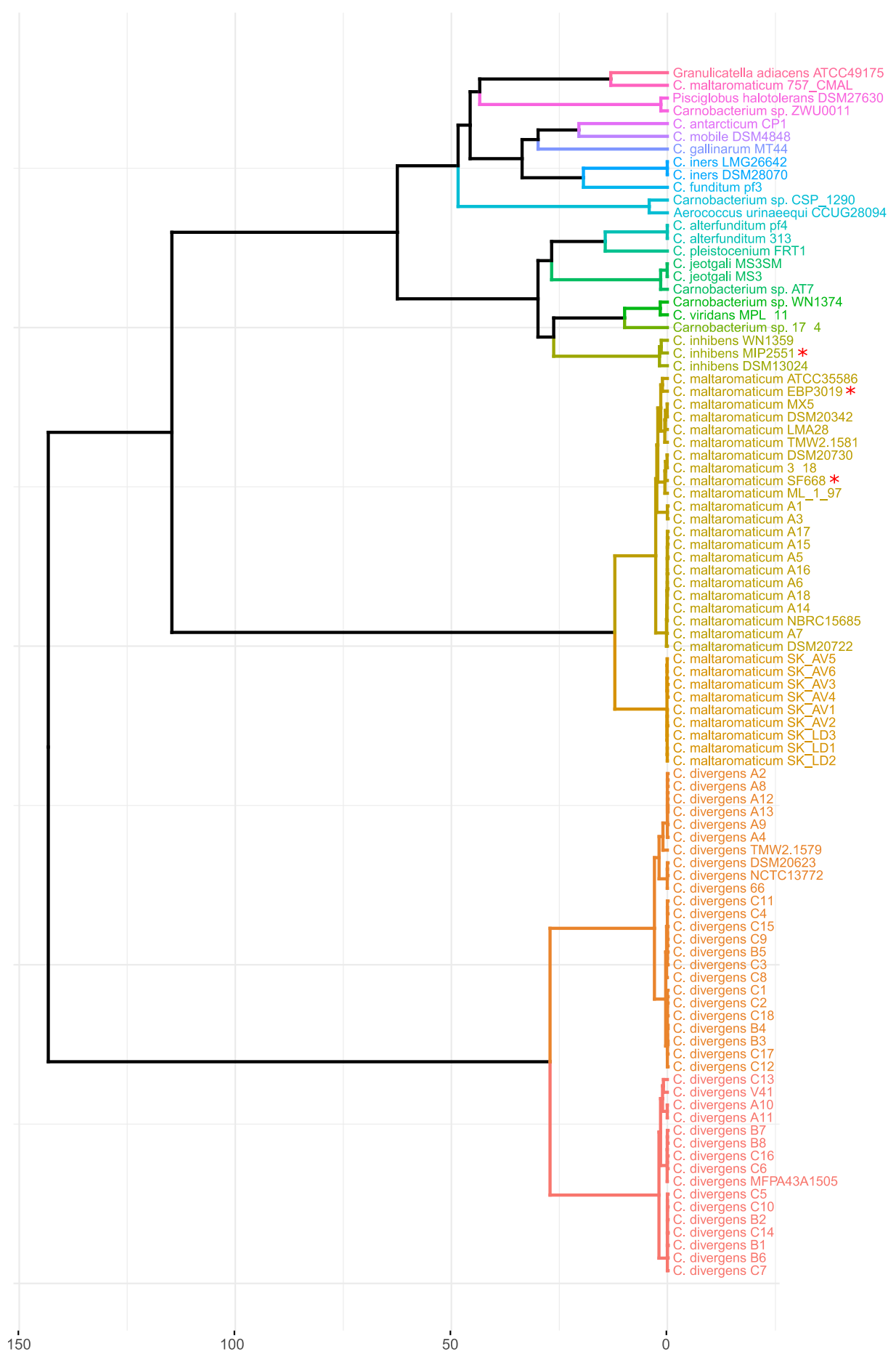

Figure 1. Average Nucleotide Identity (ANI) dendrogram of Carnobacterium spp. genomes and closed organisms-Pisciglobus halotolerans DSM27630T, Aerococcus urinaeequi CCUG28094T, and Granulicatella adiacens ATCC49175. The ANI similarity matrix was obtained with OrthoANIu (OrthoANI using USEARCH) provided by EzBioCloud. The dendrogram was constructed with RStudio using hclust \{stats\} and fviz_dend \{factoextra\}. The genomes sequenced in this study are highlighted with a red asterisk.

\subsubsection{Diversity of Antimicrobial BGCs}

A total of 67 manually annotated BGCs were considered as potentially functional since the required minimal gene set was displayed (Figures 2 and 3). At least one BGC could be predicted in 
$77 \%$ of the analyzed genomes (Figure 2). Twenty-one different BGCs were identified; 14 of them were not described in the literature until now. They were distributed into four classes of natural products (Terpenes, RiPPs, NRPS, NRPS/PKS). Carnobacterium spp. strains harbored between zero and six BGCs. Two or three BGC copies were identified in scarce cases (Figure 2). Globally, the BGC content seemed to be species-dependent. The water-sourced strains displayed specialized BGC content, but no significant difference was observed between the food strains isolated from seafood or meat products (Figure 2).

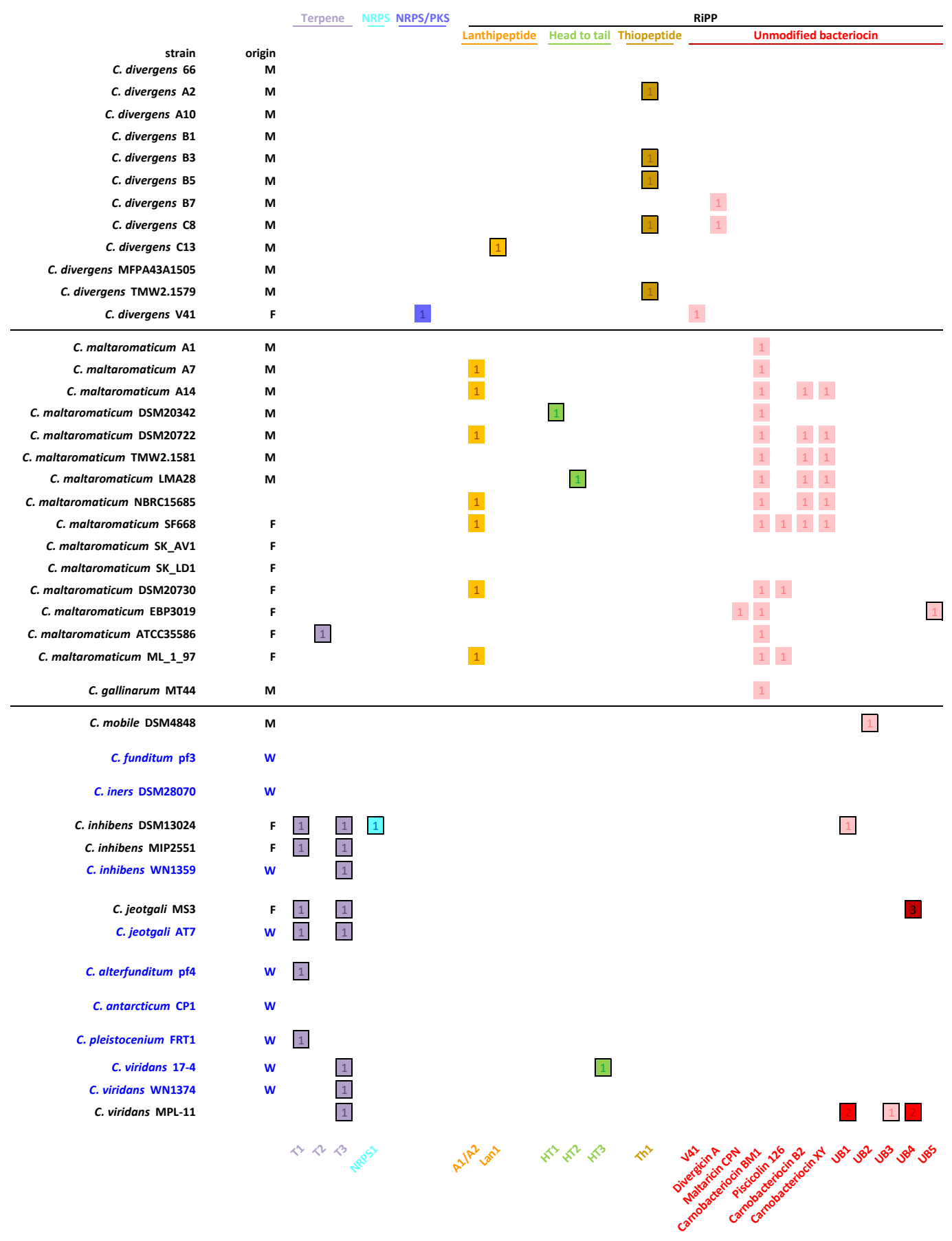

Figure 2. Predicted biosynthetic gene cluster (BGCs) in Carnobacterium spp. genomes. Numbers and color intensity indicated the copy numbers of BGCs. Strains from marine origin are colored in blue. Origin: $\mathrm{M}=$ meat; $\mathrm{F}=$ fish and seafood products; $\mathrm{W}=$ water. The three genomes sequenced in this study are highlighted with a red asterisk. 


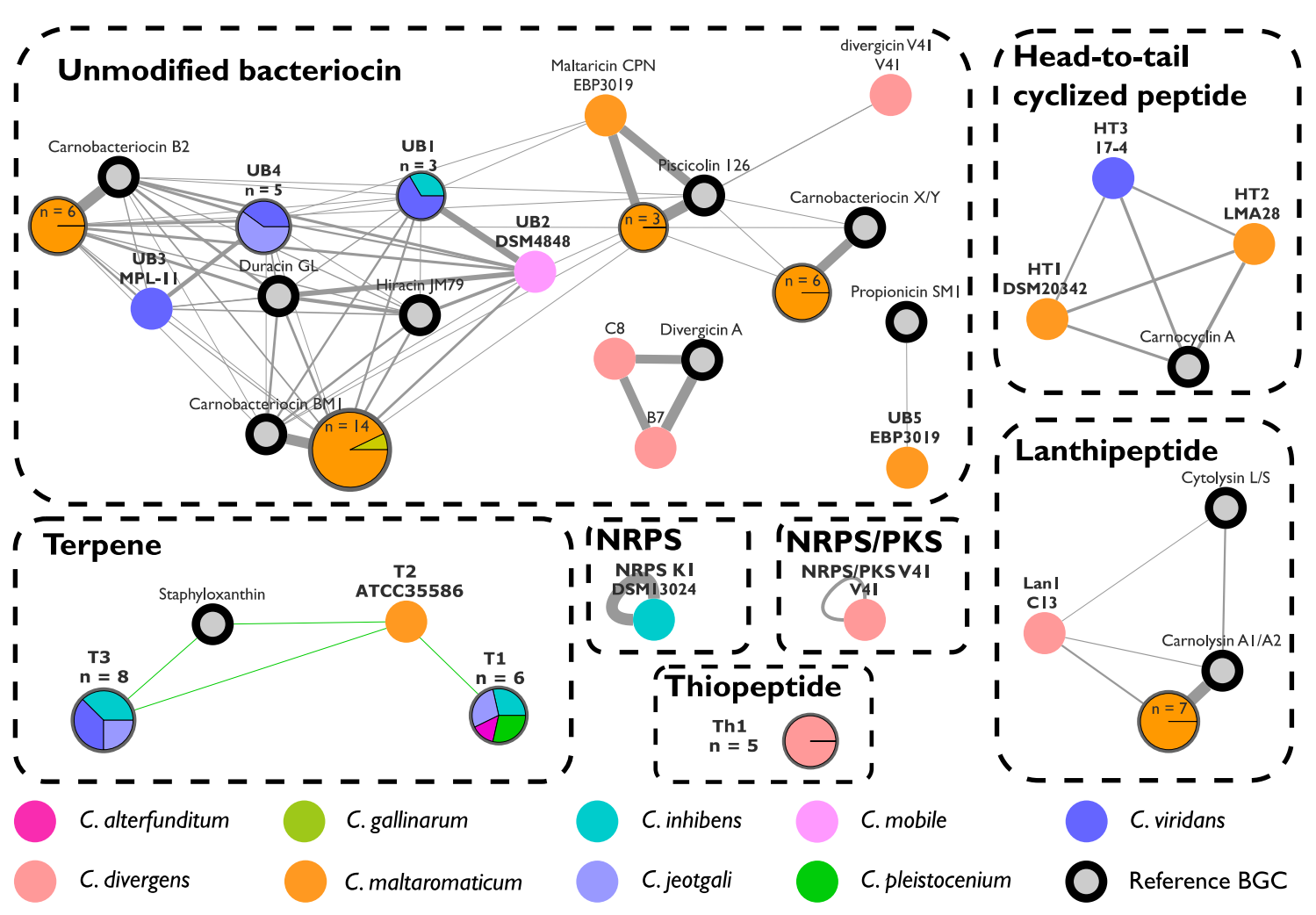

Figure 3. Sequence similarity network of Carnobacterium predicted biosynthetic gene cluster (BGCs). The network was generated with BiG-SCAPE, and graphical modifications were done with Cytoscape. A node represents a predicted BGC. For more legibility, several similar BGCs were grouped into a single node. In this case, a pie chart illustrates the represented species, and the size of the node is proportional to the number of BGCs. The thickness of the lines is correlated to the similarity between two nodes. The dotted boxes indicate the different classes of BGCs.

Terpenes are an important source of natural compounds derived from one or more isoprene unit. A total of 13 terpenes classified into three different groups (T1, T2, and T3) were predicted (Figures 2 and 3). The distribution of these terpenes appeared to be species-related and particularly distributed among environmental strains. Core clusters of T1 and T2 were only composed of, respectively, one and two biosynthetic genes related to terpenes (Figure 4). In both T1 and T2, one gene coding for a putative phytoene/squalene synthase was predicted with a conserved isoprenyl diphosphate synthase domain $(T 1 A, T 2 A)$. This enzyme is generally involved in the formation of the linear backbone of isoprenoid compounds [49]. $T 2 B$, an additional gene encoding a bacterial-type phytoene desaturase involved in tetraterpene biosynthesis such as carotenoids, was predicted in the cluster T2 [50]. The T3 BGC was more complex and was composed of six core biosynthetic genes, which code for proteins similar to those in the staphyloxanthin BGC from Staphylococcus aureus (Figure 3) with the protein sequence identity varying between $38.3 \%$ and $58.9 \%$. Staphyloxanthin is a carotenoid pigment promoting resistance to reactive oxygen species [51]. 

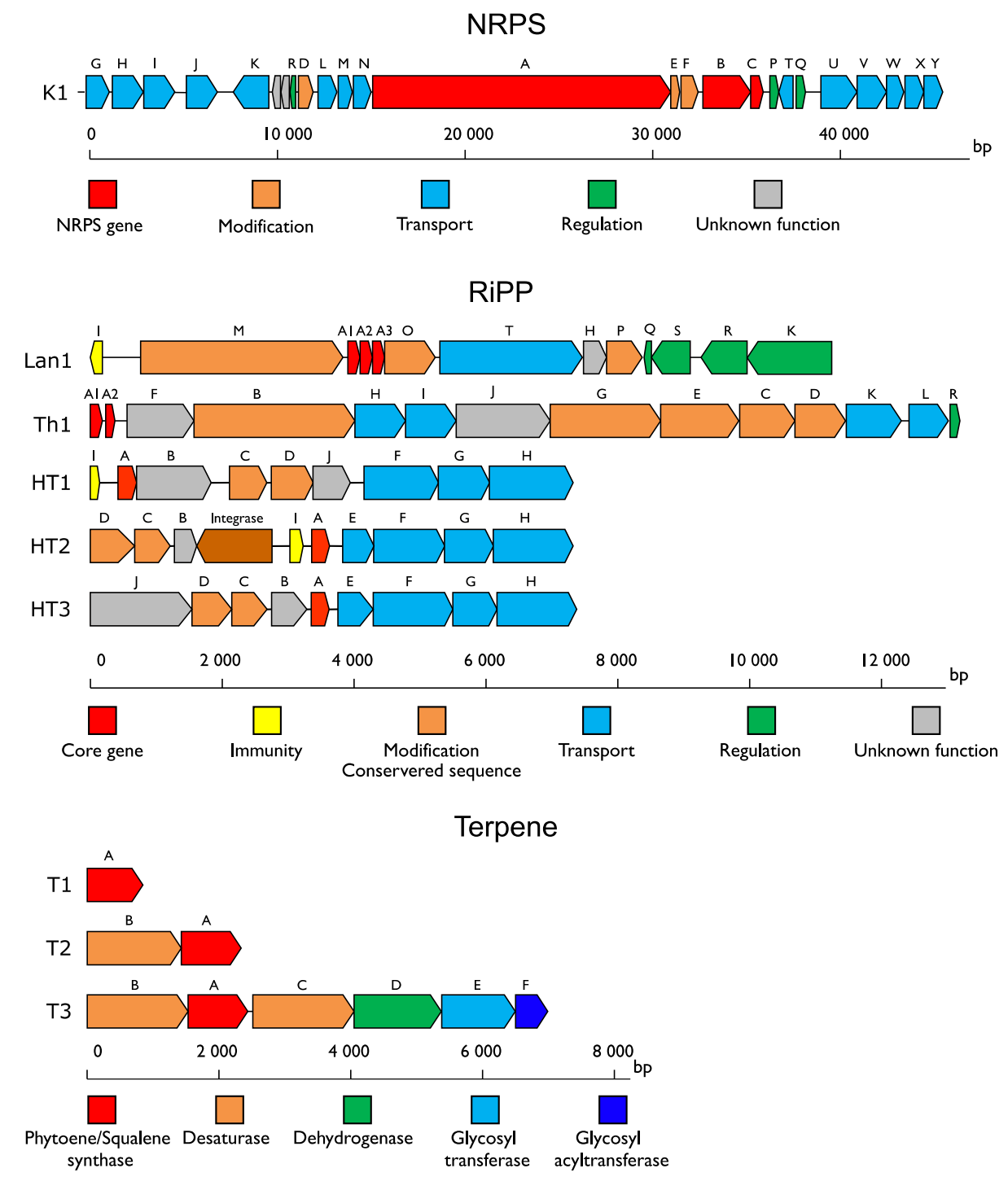

Figure 4. Undescribed biosynthetic gene cluster (BGC) structures. For each undescribed BGC, the gene length, function, and cluster organization are represented and named using letters and numbers when several core genes were predicted in the same cluster.

In addition to the known NRPS/PKS hybrid BGC from C. divergens V41, only one NRPS BGC was detected (Figures 2 and 3). The new $43 \mathrm{~kb}$-long NRPS cluster found in the $C$. inhibens DSM13024 strain (also named K1) was composed of an NRPS gene consisting of five complete domain modules $(k 1 A)$ and of a second gene containing the termination module $(k 1 B)$ [52] followed by a phosphopantethienyl transferase ( $k 1 C)$ [53] (Figure 4). Genes involved in transport or regulation (k1G-k1Y), as well as putative auxiliary genes, including a S-adenosyl-L-methionine (SAM)-dependent methyltransferase $(k 1 D)$, an aspartate decarboxylase, and a phosphohydrolase ( $k 1 E$ and $k 1 F)$ were also identified.

Two different lanthipeptide BGCs were predicted (Figures 2 and 3). The two-component lanthipeptide carnolysin A1/A2 [54] was detected in approximately half of the C. maltaromaticum strains (Figure 2). The amino acid sequence comparison revealed a $100 \%$ identity between all predicted canolysin A1/A2 BGCs. A new lanthipeptide BGC, named Lan1, was found in the C. divergens C13 strain. The cluster encompassed a lanM lanthionine synthetase gene, indicating a class II lanthipeptide [13], followed by three potential precursor peptides (Lan1A1, Lan1A2, and Lan1A3), and a transport system (Figure 4). The best similarity was found with the undescribed sequences from Bacillus thuringiensis with an amino acid identity below $68 \%$ (Table 1 ). 
Table 1. Undescribed ribosomally synthesized and post-translationally modified peptides (RiPPs) sequence prediction. Names were arbitrarily given depending on predicted RiPP classes. Sequence prediction was achieved with AntiSMASH, and the BAGEL leader sequence was predicted with SignalP 5.0. Alignment by Blastp of the core sequence to the non-redundant protein sequence database (nr) was used to predict the RiPP class and the closest known RiPP.

\begin{tabular}{|c|c|c|c|c|c|c|}
\hline Gene Name & Leader Peptide & Core Sequence & Blastp Prediction & Best Match & Identity & Similarity \\
\hline Lan1A1 & - & $\begin{array}{l}\text { MQTTTKSFVGQAFEELSIEEMEVLQGS } \\
\text { GDVQPLSSPVSWIATALSAVLCFPGSV }\end{array}$ & type 2 lantibiotic & Bacillus thuringiensis & $48 \%$ & $72 \%$ \\
\hline Lan1A2 & - & $\begin{array}{l}\text { MITNQFIGQAFEELSTEEMEVLQGAGE } \\
\text { ITPYSTIPCAAIISAVWATITKC }\end{array}$ & type 2 lantibiotic & Bacillus thuringiensis & $68 \%$ & $85 \%$ \\
\hline Lan1A3 & - & $\begin{array}{l}\text { MESKELHQFVGQAFEELSIESMEQLQG } \\
\text { SSDISPRTTLPCLESAVVSYEIITMIFCKS }\end{array}$ & type 2 lantibiotic & Bacillus thuringiensis & $65 \%$ & $72 \%$ \\
\hline Th1A1 & MEKELSTKDFDLEVELLDLDEVSA & IPETTASSGSTSCSASSTCGSTSCCGSC & thiazolyl-peptide & Enterococcus termitis & $100 \%$ & $100 \%$ \\
\hline Th1A2 & $\begin{array}{c}\text { MERELSVNETTTEDFDLEVELLDS } \\
\text { DEVSA }\end{array}$ & IPETTASSGSTSCSASSTCGSTSCCGSC & thiazolyl-peptide & Enterococcus termitis & $100 \%$ & $100 \%$ \\
\hline HT1 & $\begin{array}{l}\text { MMNVRLTKNYKFYGAISLVLISITI } \\
\text { GILFISTTPYIAGA }\end{array}$ & $\begin{array}{l}\text { LGLSTGTATQVVSLISAYQTAAAIVSIVGAL } \\
\text { TGVGGITSGIVATVLFLLKKQGKAKAALW } \\
\text { MSDLIMEIASSMGISWGVASKVIDLVLAGS }\end{array}$ & circular bacteriocin & $\begin{array}{c}\text { Streptococcus } \\
\text { pseudopneumoniae }\end{array}$ & $67 \%$ & $80 \%$ \\
\hline HT2 & - & $\begin{array}{l}\text { SAWAIVAAIVSGGGIIAIGAVAIKALIQSKL } \\
\text { KQMGRAAVITW }\end{array}$ & circular bacteriocin & Paenibacillus larvae & $49 \%$ & $70 \%$ \\
\hline HT3 & - & $\begin{array}{l}\text { MIELTMELMNSMNIGRSTATHVIDLAVAG } \\
\text { ASAWAIVASIAAGGGIIAIGAVAVRTLIKSK } \\
\text { LKKLGYTALVAW }\end{array}$ & circular bacteriocin & Paenibacillus larvae & $49 \%$ & $70 \%$ \\
\hline UB1 & MVSGLGLLFSSINVEAATA & $\begin{array}{l}\text { YPNGVYCNKTKCWVDWNKAQSEIGKIIV } \\
\text { NGWVQSGPWS }\end{array}$ & duracin GL & Enterococcus durans & $82 \%$ & $86 \%$ \\
\hline UB2 & $\begin{array}{c}\text { MKKNLIKFATVFILVSGLGLLFSSI } \\
\text { NAEAATA }\end{array}$ & $\begin{array}{l}\text { YPNGVYCNKTKCWVDWNKAQSEIGKIIV } \\
\text { NGWIQNGPWS }\end{array}$ & duracin GL & Enterococcus durans & $79 \%$ & $89 \%$ \\
\hline UB3 & 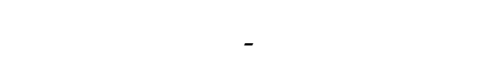 & $\begin{array}{c}\text { MNGNGVSCTKTKCSVNWGQALTEGTKR } \\
\text { WGDNLFGSVSG }\end{array}$ & hiracin-JM79 & Enterococcus faecalis & $79 \%$ & $80 \%$ \\
\hline UB4 & $\begin{array}{c}\text { MGKKILKGLIVSIFLLGIVLFIAPQ } \\
\text { EAEA }\end{array}$ & $\begin{array}{l}\text { STYYGNGVSCTKKKCSVNWGQSWTEGV } \\
\text { QRWGDHLFG }\end{array}$ & hiracin-JM79 & Enterococcus faecalis & $75 \%$ & $91 \%$ \\
\hline UB5 & $\begin{array}{l}\text { MIGEMKMKKNLLFFVVFVLSLSV } \\
\text { TPMLASA }\end{array}$ & $\begin{array}{l}\text { ESENKVDMLPDGTTFTFGVPFTTNEFSDD } \\
\text { GSYETVTIVSEVTNNTSSSVNIGITPRRIDN } \\
\text { GYYIGRAYWINRNGLLSVSIYPNKGASGW } \\
\text { TKDRAWDELKRNFSHYANWKNETSLRKQF } \\
\text { NCHARPIPPYTGKIPWNLEPSKAATNILTCN }\end{array}$ & propionicin SM1 & $\begin{array}{l}\text { Propionibacterium } \\
\text { jensenii DF1 }\end{array}$ & $34 \%$ & $49 \%$ \\
\hline
\end{tabular}


Only one thiopeptide BGC was predicted in a half of the C. divergens strains (Th1) (Figure 2). Thiopeptides are RiPPs containing characteristic thiazole rings, described for the first time in Carnobacterium genus. The core cluster was composed of two structural genes, named th1A1 and th1A2, with identical sequences (Figure 4 and Table 1). Genes encoding enzymes involved in the structural backbone of the thiopeptide were predicted (e.g., formation of piperidine, dehydropiperidine and pyridine macrocycle, thiazole and thiazoline macrocycle, and Dha and Dhb residues) [13]. They included two LanB-like dehydratases ( $t h 1 B$ and $t h 1 C)$, a potential enzyme involved in cycloaddition $(t h 1 D)$, and a cyclodehydratase $(t h 1 G)$. The genes involved in the regulation and transport were also predicted, including a putative cyclic autoinducer peptide $(t h 1 R)$. Th1 showed a $100 \%$ identity with the uncharacterized thiopeptide core sequence of Enterococcus termitis (Table 1).

Only one head to tail cyclized peptide (HT) named carnocyclin A has been reported in Carnobacterium species [55], but it was not found in any genome analyzed in this study (Figure 3). Three undescribed HT, namely HT1, HT2, and HT3, with original core sequences were predicted in C. maltaromaticum and C. viridans (Figure 2 and Table 1). Their molecular mass was estimated between 5.89 and $7.32 \mathrm{kDa}$.

Among the predicted RiPPs, 37 out of 52 encoded unmodified bacteriocins (UBs). They were divided into 10 different BGCs. Most of the UBs were identified in C. maltaromaticum genomes (Figures 2 and 3). The carnobacteriocin BM1 BGC [56] was found in the C. gallinarum MT44 genome and in $85 \%$ of the C. maltaromaticum genomes. Other described UBs were exclusively found in genomes of C. maltaromaticum species-the piscicolin 126 BGC [57] in 15\% of the genomes, and the carnobacteriocin B2 and X/Y BGCs [56,58] in 38\% of the genomes. The divergicin A BGC [59] was identified in the C. divergens B7 and C8 strains and the divercin V41 BGC [48] only in the V41 strain. Four uncharacterized UBs were also predicted in the food-isolated strains C. inhibens DSM 13024 (UB1), C. jeotgali MS3 (UB4), C. mobile DSM 4848 (UB2), and C. viridans MPL-11 (UB1, UB3, and UB4) (Figure 2). All four novel genes encoded similar proteins (from 50\% to 95\% identity to each other) (Figure 3). UB1 and UB2 displayed amino acid similarity with the Enterococcus durans duracin GL, whereas UB3 and UB4 with Enterococcus faecalis hiracin-JM79 [60,61] (Table 1 and Figure 3).

\subsection{Antimicrobial Activities of Carnobacterium spp. Isolated from Seafood Products}

\subsubsection{Inhibition Profiles of Carnobacterium spp. Strains}

Two hundred sixty Carnobacterium spp. strains from seafood products, including 211 C. maltaromaticum, 45 C. divergens, 3 C. jeotgali, 2 C. inhibens, 1 C. funditum, and 1 C. viridans strains were studied. Reference strains C. alterfunditum CIP 105796, C. divergens CIP 101029, C. funditum DSM 5970, C. gallinarum NCDO 2766, C. inhibens DSM 13024 and WN1359, C. jeotgali KCTC 13251, C. maltaromaticum CIP 103158, and NCDO 2672, C. mobile CIP 103159, C. pleistocenium CIP 108033, and C. viridans MPL-11 were added to this study. Each Carnobacterium species was then represented except for C. iners and C. antarcticum, which have been recently described $[62,63]$. The antimicrobial activity profile of these strains was evaluated against 17 indicator bacteria, yeast, and fungi (Table S3).

No inhibition of Candida albicans and Pseudomonas fluorescens was observed. Approximately $60 \%$ of the Carnobacterium spp. strains showed antimicrobial activity against at least one of the indicator strains tested. Overall, different inhibition patterns were observed depending on the strain species (Figure 5). C. maltaromaticum inhibited all Gram-positive species except Staphylococcus epidermidis. In contrast, other Carnobacterium species inhibited Escherichia coli, Vibrio parahaemolyticus, Morganella morganii, Staphylococcus epidermidis, and Aspergillus fumigatus. Interestingly, the C. inhibens MIP2551 strain was the sole strain able to inhibit Aeromonas salmonicida, Vibrio harveyi, and Chromobacterium violaceum. 


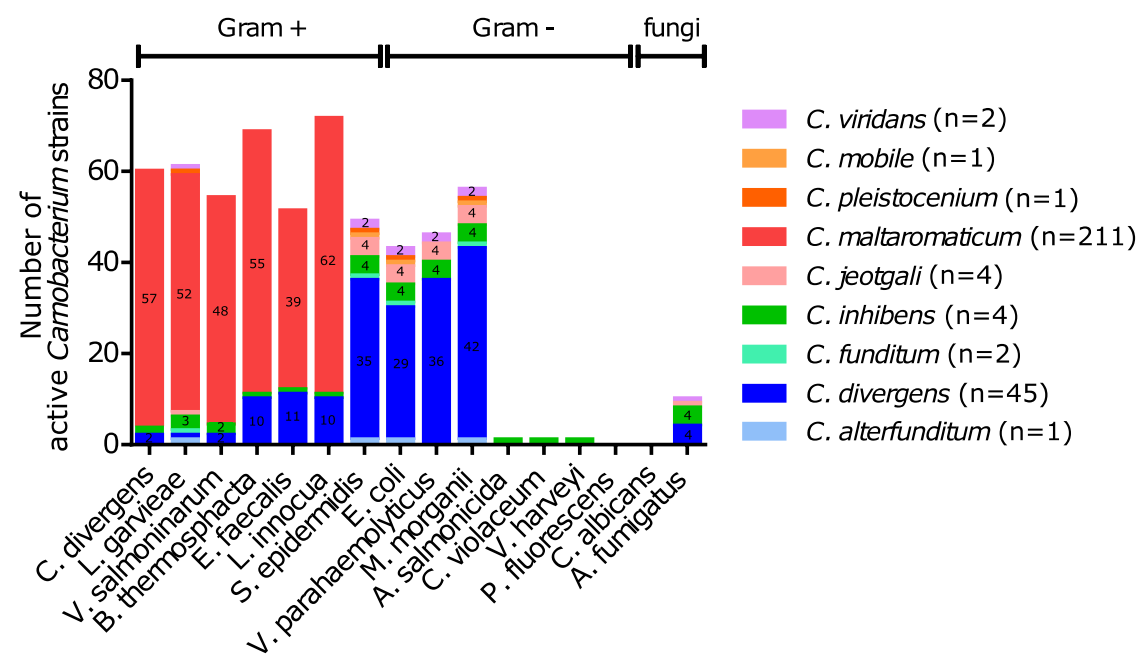

Figure 5. The number of active Carnobacterium spp. strains according to the species. Carnobacterium spp. strain cultures were spotted on agar plates inoculated with one of the indicator strains. A strain was considered active when the presence of an inhibitory halo could be observed. The number of active strains was indicated inside the bar for species represented by more than one strain. $n$ : total number of Carnobacterium spp. strains tested per species.

\subsubsection{Involvement of $\mathrm{H}_{2} \mathrm{O}_{2}$ Inhibition}

The addition of catalase into the medium resulted in the loss of the inhibitory effect for $56 \%$ of the active Carnobacterium spp. strains (Table S3). $\mathrm{H}_{2} \mathrm{O}_{2}$ production is involved in the inhibition mechanism of S. epidermidis, E. coli, M. morganii and V. parahaemolyticus by C. viridans, C. mobile, C. pleistocenium, C. jeotgali, C. funditum, C. alterfunditum, $C$. inhibens, and by $67 \%$ of $C$. divergens strains. The $C$. inhibens MIP2551 strain was the highest producer of $\mathrm{H}_{2} \mathrm{O}_{2}$; its production time-course was monitored for $24 \mathrm{~h}$ and compared to Lactococcus garvieae, a species known to produce high inhibitory amounts of $\mathrm{H}_{2} \mathrm{O}_{2}$ (Figure 6). In optimal aeration conditions, the MIP2551 strain began to produce $\mathrm{H}_{2} \mathrm{O}_{2}$ during the exponential phase and reached a maximal concentration of $150 \mathrm{mg} / \mathrm{L}$ on the stationary phase, with a maximal $\mathrm{OD}_{600 \mathrm{~nm}}$ of 0.3 . This concentration was five times higher than those observed for Lactococcus garvieae strain. The same $\mathrm{H}_{2} \mathrm{O}_{2}$ production profile was observed for C. inhibens CD344, DSM 13024, and WN1359 strains (data not shown).

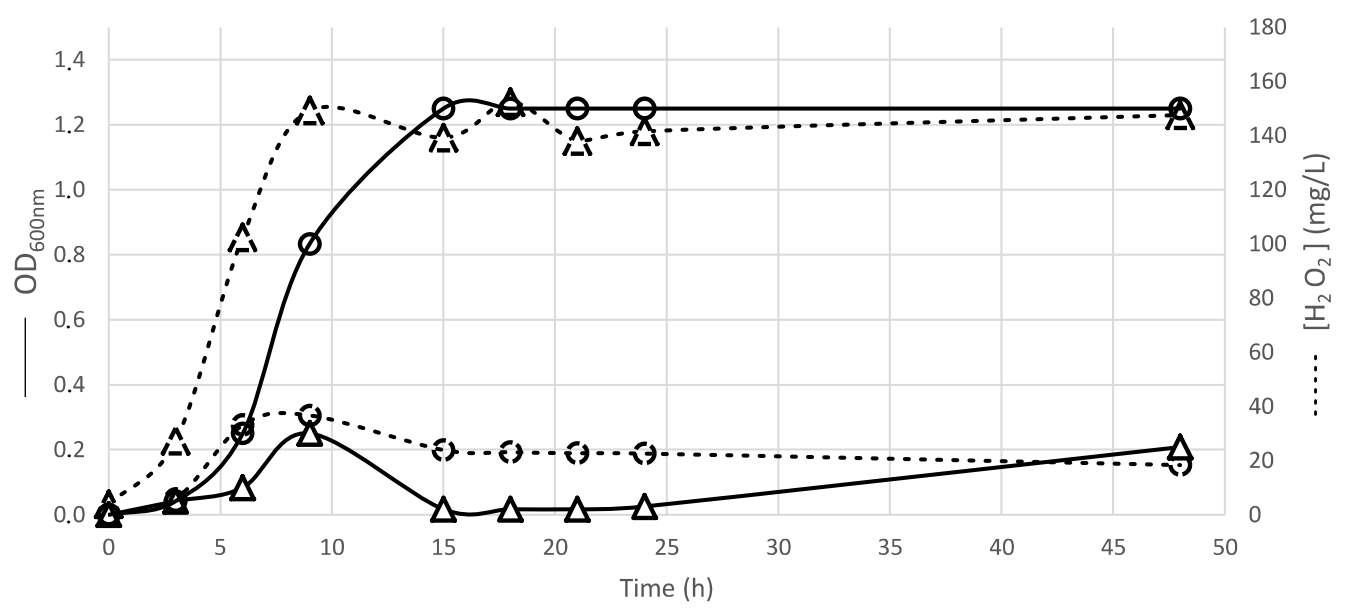

Figure 6. Assessment of $\mathrm{H}_{2} \mathrm{O}_{2}$ production during the growth of Carnobacteriun inhibens MIP2551 (triangle) and Lactococcus garvieae CIP102507 (circle). Dashed lines: $\mathrm{H}_{2} \mathrm{O}_{2}$ concentration estimated by Dosatest ${ }^{\circledR}$ Peroxide test strips; Solid lines: OD measured at $600 \mathrm{~nm}$. Strains were cultivated at $26^{\circ} \mathrm{C}$, in brain heart infusion (BHI) medium and in shaking conditions. 


\subsubsection{Comparison of CFSs Activities}

Sixty-five strains (56 C. maltaromaticum and nine C. divergens) remained active after catalase treatment (Table S3). Their cell-free supernatants (CFSs) were tested against Lactococcus garvieae and L. monocytogenes. All the 65 CFSs found active against $L$. monocytogenes remained active, suggesting an extracellular active compound. However, only three CFSs remained active against Lactococcus garvieae. C. maltaromaticum SF668 was the only strain with a CFS active against both bacterial targets. After digestion by proteinase K, all CFSs became inactive, suggesting a peptidic nature for antimicrobial compounds, such as bacteriocins.

CFS efficacy against L. monocytogenes was determined and compared for all active strains. The growth of L. monocytogenes was measured in CFS-supplemented medium. The 65 active CFSs were diluted to determine the minimal inhibitory dilution (MID) (Figure 7). The MID varied from less than 2 to 256 for $C$. divergens, and less than 2 to 2048 for C. maltaromaticum strains. Seventy one percent C. maltaromaticum CFSs (40 out of 56) and $22 \%$ C. divergens CFSs (two out of nine) showed a MID $\geq 256$. This result suggested higher activity for $C$. maltaromaticum strains. The $C$. divergens V41, which produces the antilisterial divercin V41 (Table S1) displayed a MID = 16 in the tested conditions. Three $C$. divergens strains, namely CD317, CD320, and CD349, showed higher activity than the $C$. divergens V41 strain. C. maltaromaticum V1 strain, which produces the previously described carnobacteriocin BM1 and piscicolin 126 [64] (Table S1), and the EBP3019 and SF668 strains belonged to the most efficient CFS group. A MID greater than 512 was only detected in the EBP3019 strain. This result was confirmed by supplementary triplicate assays allowing the estimation of an average MID of 1024.

\subsection{MIP2551, EBP3019, and SF668 Genome Specificities}

It appeared from all these analyses that C. maltaromaticum EBP3019 and SF668 strains displayed interesting antimicrobial activities related to extracellular peptides. SF668 strain was previously shown to have antilisterial effect in cold-smoked salmon and used as bioprotective strain [25]. In addition, $C$. inhibens MIP2551 was shown to produce high amounts of $\mathrm{H}_{2} \mathrm{O}_{2}$. In order to identify potentially original antimicrobial BGCs, the genomes of these three strains were sequenced, assembled, and annotated. Phylogenomic analysis by ANI similarity values for these three strains confirmed the identification using partial $16 \mathrm{~S}$ rDNA sequencing (Figure 1).

Genes coding for $\mathrm{H}_{2} \mathrm{O}_{2}$ anabolism and catabolism were identified in the MIP2551 genome and compared to other species (Figure 8). In most cases, it seemed to be species dependent. The catalase gene involved in $\mathrm{H}_{2} \mathrm{O}_{2}$ catabolism was found in MIP2551, and in $88 \%$ of the analyzed genomes. Genes coding for the oxidases GplO, Pox, and Lox were found in C. inhibens MIP2551 genome. This genetic content was similar to environmental species, which is consistent with $\mathrm{H}_{2} \mathrm{O}_{2}$ inhibition in our bioassay (excepted for $C$. antarcticum not represented). Two to three genes coding for Lox were detected in some genomes as in MIP2551. 


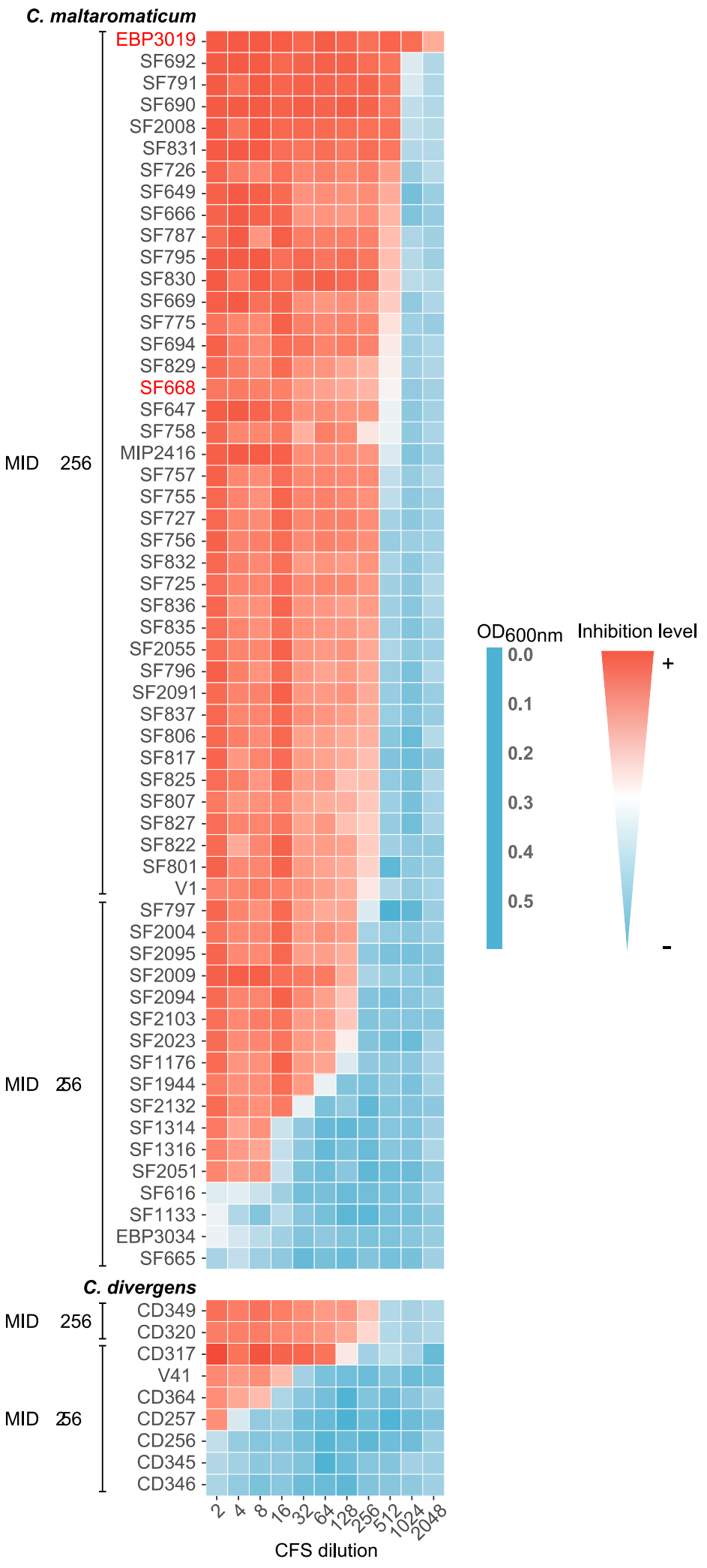

Figure 7. Cell-free supernatant (CFS) efficacy against Listeria monocytogenes RF191. The efficacy was evaluated for each strain of Carnobacterium spp. by determining their minimal dilution inhibiting the growth of Listeria monocytogenes RF191 (MID). The growth of the strain RF191 was measured through $\mathrm{OD}_{600 \mathrm{~nm}}$. EBP3034 strain was used as a negative control. Genomes sequenced in this study are highlighted in red. 


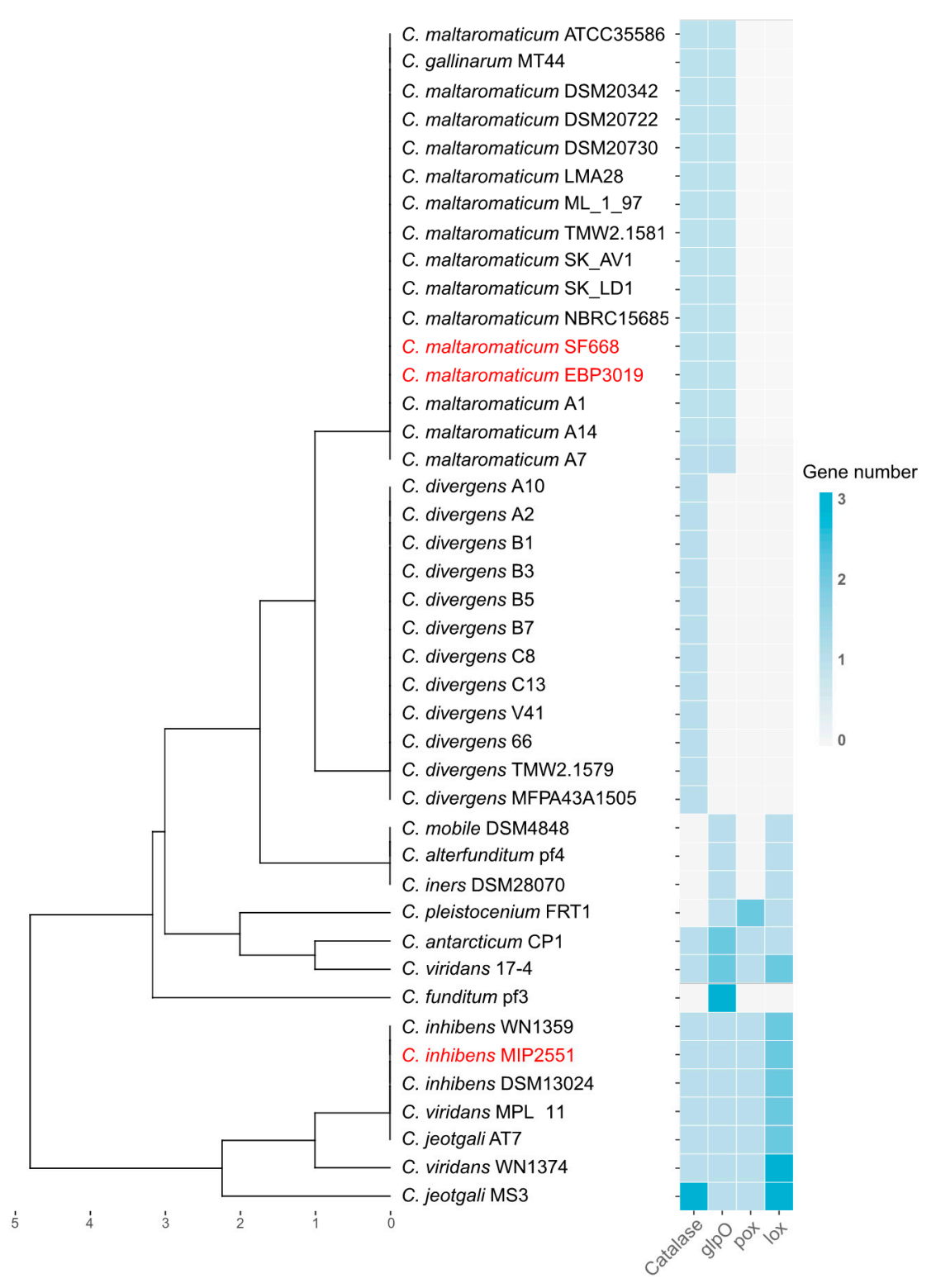

Figure 8. Hierarchical clustering of Carnobacterium spp. genomes by the presence of $\mathrm{H}_{2} \mathrm{O}_{2}$ production and decomposition genes: Lactate oxidase (lox, EC.1.13.12.4), pyruvate oxidase (pox, EC.1.2.3.3), $\alpha$-glycerophosphate oxidase ( $g l p O, E C .1 .1 .3 .21)$, and catalase (EC.1.11.1.6). Genomes sequenced in this study are highlighted in red.

The BGC content of the C. inhibens MIP2551, C. maltaromaticum EBP3019, and SF668 strains was investigated, and the predicted clusters were dereplicated. The two undescribed terpene BGCs T1 and T3 were predicted in C. inhibens MIP2551 genome. A total of five RiPPs were predicted in the SF668 strain, identified as carnolysin A1/A2, piscicolin 126, carnobacteriocin BM1, B2, and X/Y (Figure 2). This equipment corresponded to the largest RIPPs BGC diversity among the Carnobacterium spp. genomes. Three RiPPs BGCs were predicted for the C. maltaromaticum EBP3019 strain-the highly conserved carnobacteriocin BM1 and the maltaricin CPN BGC [26] along with a new UB named UB5 (Figures 2 and 3). This last BGC displayed the best sequence similarity (49\%) with propionicin SM1 from Propionibacterium jensenii [65] (Table 1). UB5 is probably extracellular and has a high molecular weight $(16.86 \mathrm{kDa})$. 


\section{Discussion}

The use of phylogenomics and, in particular, the analysis of ANI allows new insights into genome evolution and bacterial species definition $[66,67]$. Within the genus Carnobacterium, only the species C. alterfunditum and C. pleistocenium cannot be distinguished on the basis of $16 \mathrm{~S}$ rDNA alone. In this study, a combination of $16 \mathrm{~S}$ rDNA-based phylogeny and ANI similarity ensured accurate strain identification.

The constitution of a reliable Carnobacterium spp. genome dataset allowed us to discriminate BGC content depending on species and ecological niches. The number of BGCs, and the class of the predicted molecules appeared to be generally species-specific. For example, carnolysin A1/A2 and carnobacteriocin BM1 are specifically found in C. maltaromaticum and thiopeptide Th1 in C. divergens strains. The food-sourced species $C$. maltaromaticum appeared to be particularly rich in RiPPs, as well as $C$. divergens to a lesser extent. These observations could be related to their adaptation to animal and food product habitats as previously described [20]. In the same way, RiPPs with original sequences, were identified in strains belonging to the environmental species $C$. jeotgali, $C$. inhibens, and C. viridans but isolated in food products (Figure 2). The acquisition of RiPPs in these environmental species could be due to the adaptation to fight against Gram-positive strains largely present in the food microbiome and absent in oceans. This is consistent with a previous study showing that the MIP2551 strain lacking in RiPPs was not competitive in salmon gravlax [68]. Other BGC such as terpene were exclusively predicted in environmental species, with the exception of BGC T2. Terpenes are less studied in bacteria than in plants or fungi, but they do represent a promising source of bioactive compounds. This class of BGCs has not been described yet in the genus Carnobacterium. More genome sequences for each species are needed to confirm these observations.

In this study, C. divergens and C. maltaromaticum isolated from seafood products represented more than $95 \%$ of the isolated strains, a ratio which is consistent with that observed in the metagenomic analyses of food [20]. No activity related to the acidification or the production of organic acids was detected in our experiments, which reinforces data from previous studies [69,70]. Genomic analyses revealed the presence of BGCs in most of the C. maltaromaticum and C. divergens strains while only $60 \%$ of the tested isolates were active. Thanks to the reference strains screened for antimicrobial activity, we also observed that some of them showed no activity despite the presence of terpene, NRPS and RiPPs in their genome (e.g., C. mobile DSM4848, C. inhibens DSM13024, C. viridans MPL-11). Since these BGCs remain undescribed, it could be hypothesized that they encode molecules devoid of antimicrobial activity, or active against other strains not tested in this screening. BGCs might also not be expressed under the culture conditions used. Further investigations using culturomic analyses or co-cultures could help to activate such cryptic BGCs [71,72].

The antimicrobial screening showed that environmental Carnobacterium species such as $C$. inhibens, C. jeotgali, C. viridans more likely inhibit bacterial growth through $\mathrm{H}_{2} \mathrm{O}_{2}$ accumulation. $\mathrm{High} \mathrm{H}_{2} \mathrm{O}_{2}$ level was in accordance with genomic differentiation of niche species, particularly the presence of lox and pox genes compared to $C$. maltaromaticum. Most $C$. divergens strains also produced $\mathrm{H}_{2} \mathrm{O}_{2}$ without harboring the known oxidase encoding genes $l o x$, pox, and $g l p O$ (Figure 8). Lox gene encodes the lactate oxidase responsible for the conversion of lactic acid into pyruvate. It can then be hypothesized that the presence of both lox and pox genes gives a double advantage to outcompete other microorganisms not only through nutritional competition but also through the production of antimicrobial compounds. C. inhibens, C. jeotgali, and $C$. viridans species harbor multiple copies of genes encoding Lox probably correlated with $\mathrm{H}_{2} \mathrm{O}_{2}$ production [73], and in parallel the T3 BGC similar to staphyloxanthin-encoding BGC, which has protective properties against $\mathrm{H}_{2} \mathrm{O}_{2}$. A staphyloxanthin-similar function can, therefore, be assumed for the T3 cluster, although no xantho-pigment was produced by the T3 cluster containing strains.

\section{Conclusions}

Combining genome mining, phenotype characterization, and dereplication on a large dataset appeared a relevant approach to avoid rediscovering known active molecules and their BGCs. Thanks 
to this strategy, new insights into the antimicrobial potential of environmental Carnobacterium species suggests that they should be considered for further new biotechnological applications. Furthermore, BGC distribution in Carnobacterium spp. showed that the screening of active RiPPs should be performed in food-related strains. Two of them, EBP3019 and SF668, were selected for their activity against Listeria monocytogenes. Further studies on EBP3019 supernatant, such as fractionating, purification, mass analysis, and amino acid sequencing have to be conducted to isolate and characterize UB5, whose BGC was not found in any other genome.

Supplementary Materials: The following are available online at http://www.mdpi.com/2076-2607/8/7/1093/s1, Figure S1: 16S rDNA maximum likelihood phylogenic tree, Table S1: Characterized bacteriocins in Carnobacterium spp.; Table S2: Carnobacterium spp. strains and related genomes used for genome mining; Table S3: Inhibitory activity of Carnobacterium cultures and supernatants in the presence or not of catalase.

Author Contributions: Conceptualization, S.B. (Simon Begrem), O.G., C.D.-L. and D.P.; data curation, S.B. (Simon Begrem) and D.P.; formal analysis, S.B. (Simon Begrem) and D.P.; funding acquisition, F.L.; investigation, S.B. (Simon Begrem), F.I., F.G.-C., L.K. and S.B. (Sandrine Bonnetot); methodology, S.B. (Simon Begrem) and D.P.; project administration, O.G., C.D.-L. and D.P.; resources, F.L.; supervision, O.G. and C.D.-L.; validation, S.B. (Simon Begrem) and D.P.; visualization, S.B. (Simon Begrem) and D.P.; writing-original draft, S.B. (Simon Begrem) and D.P.; writing-review \& editing, O.G., C.D.-L. and D.P. All authors have read and agreed to the published version of the manuscript.

Funding: This research was funded by the European Union's Horizon 2020 research and innovation program under grant agreement No 818368 (Master). This manuscript reflects only the authors' views and the European Commission is not responsible for any use that may be made of the information it contains. Simon Begrem was supported by a fellowship from the french Ministère de l'Enseignement Supérieur et de la Recherche".

Acknowledgments: The authors would like to thank Véronique Verrez-Bagnis from Ifremer (Institut Français de Recherche pour l'Exploitation de la Mer, Nantes, France) and Marie-France Pilet (INRA-Secalim, Nantes, France) for fruitful discussions, Patrice Lepape and Carine Picot (IIciMed EA1155, Nantes, France) for the first antimicrobial screening against Candida albicans.

Conflicts of Interest: The authors declare no conflict of interest. The funders had no role in the design of the study; in the collection, analyses, or interpretation of data; in the writing of the manuscript; or in the decision to publish the results.

\section{References}

1. Kathiresan, K.; Thiruneelakandan, G. Prospects of lactic acid bacteria of marine origin. Indian J. Biotechnol. 2008, 7, 170-177.

2. Lindgren, S.E.; Dobrogosz, W.J. Antagonistic activities of lactic acid bacteria in food and feed fermentations. FEMS Microbiol. Rev. 1990, 7, 149-163. [CrossRef] [PubMed]

3. Piard, J.C.; Desmazeaud, M. Inhibiting factors produced by lactic acid bacteria. 1. Oxygen metabolites and catabolism end-products. Le Lait 1991, 71, 525-541. [CrossRef]

4. Vuyst, L.D.; Leroy, F. Bacteriocins from Lactic Acid Bacteria: Production, Purification, and Food Applications. J. Mol. Microbiol. Biotechnol. 2007, 13, 194-199. [CrossRef] [PubMed]

5. Zacharof, M.P.; Lovitt, R.W. Bacteriocins Produced by Lactic Acid Bacteria a Review Article. APCBEE Procedia 2012, 2, 50-56. [CrossRef]

6. Perez, R.H.; Zendo, T.; Sonomoto, K. Circular and Leaderless Bacteriocins: Biosynthesis, Mode of Action, Applications, and Prospects. Front. Microbiol. 2018, 9, 2085. [CrossRef]

7. Mohr, K.I.; Volz, C.; Jansen, R.; Wray, V.; Hoffmann, J.; Bernecker, S.; Wink, J.; Gerth, K.; Stadler, M.; Müller, R. Pinensins: The First Antifungal Lantibiotics. Angew. Chem. Int. Ed. 2015, 54, 11254-11258. [CrossRef]

8. Dykes, G.A. Bacteriocins: Ecological and evolutionary significance. Trends Ecol. Evol. 1995, 10, $186-189$. [CrossRef]

9. Riley, M.A.; Wertz, J.E. Bacteriocins: Evolution, Ecology, and Application. Annu. Rev. Microbiol. 2002, 56, 117-137. [CrossRef]

10. Klaenhammer, T.R. Genetics of bacteriocins produced by lactic acid bacteria. FEMS Microbiol. Rev. 1993, 12, 39-85. [CrossRef]

11. Cotter, P.D.; Ross, R.P.; Hill, C. Bacteriocins-A viable alternative to antibiotics? Nat. Rev. Microbiol. 2013, 11, 95-105. [CrossRef] [PubMed] 
12. Heng, N.C.K.; Tagg, J.R. What's in a name? Class distinction for bacteriocins. Nat. Rev. Microbiol. 2006, 4, 160. [CrossRef]

13. Arnison, P.G.; Bibb, M.J.; Bierbaum, G.; Bowers, A.A.; Bugni, T.S.; Bulaj, G.; Camarero, J.A.; Campopiano, D.J.; Challis, G.L.; Clardy, J.; et al. Ribosomally synthesized and post-translationally modified peptide natural products: Overview and recommendations for a universal nomenclature. Nat. Prod. Rep. 2013, 30, $108-160$. [CrossRef] [PubMed]

14. Golomb, B.L.; Yu, A.O.; Coates, L.C.; Marco, M.L. The Lactococcus lactis KF147 nonribosomal peptide synthetase/polyketide synthase system confers resistance to oxidative stress during growth on plant leaf tissue lysate. Microbiology Open 2018, 7, e00531. [CrossRef]

15. Lin, X.B.; Lohans, C.T.; Duar, R.; Zheng, J.; Vederas, J.C.; Walter, J.; Gänzle, M. Genetic determinants of reutericyclin biosynthesis in Lactobacillus reuteri. Appl. Environ. Microbiol. 2015, 81, 2032-2041. [CrossRef]

16. Luo, Y.; Cobb, R.E.; Zhao, H. Recent Advances in Natural Product Discovery. Curr. Opin. Biotechnol. 2014, 30 , 230-237. [CrossRef]

17. Medema, M.H.; Fischbach, M.A. Computational approaches to natural product discovery. Nat. Chem. Biol. 2015, 11, 639-648. [CrossRef]

18. Ziemert, N.; Alanjary, M.; Weber, T. The evolution of genome mining in microbes-A review. Nat. Prod. Rep. 2016, 33, 988-1005. [CrossRef]

19. Passerini, D.; Beltramo, C.; Coddeville, M.; Quentin, Y.; Ritzenthaler, P.; Daveran-Mingot, M.-L.; Bourgeois, P.L. Genes but Not Genomes Reveal Bacterial Domestication of Lactococcus Lactis. PLoS ONE 2010, 5, e15306. [CrossRef]

20. Iskandar, C.F.; Borges, F.; Taminiau, B.; Daube, G.; Zagorec, M.; Remenant, B.; Leisner, J.J.; Hansen, M.A.; Sørensen, S.J.; Mangavel, C.; et al. Comparative Genomic Analysis Reveals Ecological Differentiation in the Genus Carnobacterium. Front. Microbiol. 2017, 8. [CrossRef]

21. Almeida, E.L.; Carrillo Rincón, A.F.; Jackson, S.A.; Dobson, A.D.W. Comparative Genomics of Marine Sponge-Derived Streptomyces spp. Isolates SM17 and SM18 With Their Closest Terrestrial Relatives Provides Novel Insights Into Environmental Niche Adaptations and Secondary Metabolite Biosynthesis Potential. Front. Microbiol. 2019, 10, 1713. [CrossRef]

22. Blunt, J.W.; Carroll, A.R.; Copp, B.R.; Davis, R.A.; Keyzers, R.A.; Prinsep, M.R. Marine natural products. Nat. Prod. Rep. 2018, 35, 8-53. [CrossRef] [PubMed]

23. Andryukov, B.G.; Mikhaylov, V.V.; Besednova, N.N.; Zaporozhets, T.S.; Bynina, M.P.; Matosova, E.V. The Bacteriocinogenic Potential of Marine Microorganisms. Russ. J. Mar. Biol. 2018, 44, 433-441. [CrossRef]

24. Leisner, J.J.; Laursen, B.G.; Prévost, H.; Drider, D.; Dalgaard, P. Carnobacterium: Positive and negative effects in the environment and in foods. FEMS Microbiol. Rev. 2007, 31, 592-613. [CrossRef] [PubMed]

25. Brillet, A.; Pilet, M.-F.; Prevost, H.; Bouttefroy, A.; Leroi, F. Biodiversity of Listeria monocytogenes sensitivity to bacteriocin-producing Carnobacterium strains and application in sterile cold-smoked salmon. J. Appl. Microbiol. 2004, 97, 1029-1037. [CrossRef]

26. Hammi, I.; Delalande, F.; Belkhou, R.; Marchioni, E.; Cianferani, S.; Ennahar, S. Maltaricin CPN, a new class Ila bacteriocin produced by Carnobacterium maltaromaticum CPN isolated from mould-ripened cheese. J. Appl. Microbiol. 2016, 121, 1268-1274. [CrossRef]

27. Wiernasz, N.; Cornet, J.; Cardinal, M.; Pilet, M.-F.; Passerini, D.; Leroi, F. Lactic Acid Bacteria Selection for Biopreservation as a Part of Hurdle Technology Approach Applied on Seafood. Front. Mar. Sci. 2017, 4. [CrossRef]

28. Jöborn, A.; Dorsch, M.; Olsson, J.C.; Westerdahl, A.; Kjelleberg, S. Carnobacterium inhibens sp. nov., isolated from the intestine of Atlantic salmon (Salmo salar). Int. J. Syst. Evol. Microbiol. 1999, 49, 1891-1898. [CrossRef]

29. Rafiq, M.; Hayat, M.; Anesio, A.M.; Jamil, S.U.U.; Hassan, N.; Shah, A.A.; Hasan, F. Recovery of metallo-tolerant and antibiotic resistant psychrophilic bacteria from Siachen glacier, Pakistan. PLoS ONE 2017, 12. [CrossRef]

30. Remenant, B.; Borges, F.; Cailliez-Grimal, C.; Revol-Junelles, A.-M.; Marché, L.; Lajus, A.; Médigue, C.; Pilet, M.-F.; Prévost, H.; Zagorec, M. Draft Genome Sequence of Carnobacterium divergens V41, a BacteriocinProducing Strain. Genome Announc. 2016, 4, e01109-16. [CrossRef]

31. Edgar, R.C. MUSCLE: Multiple sequence alignment with high accuracy and high throughput. Nucleic Acids Res. 2004, 32, 1792-1797. [CrossRef] [PubMed] 
32. Tamura, K.; Stecher, G.; Peterson, D.; Filipski, A.; Kumar, S. MEGA6: Molecular Evolutionary Genetics Analysis version 6.0. Mol. Biol. Evol. 2013, 30, 2725-2729. [CrossRef] [PubMed]

33. Yoon, S.-H.; Ha, S.-M.; Lim, J.; Kwon, S.; Chun, J. A large-scale evaluation of algorithms to calculate average nucleotide identity. Antonie Van Leeuwenhoek 2017, 110, 1281-1286. [CrossRef] [PubMed]

34. Bankevich, A.; Nurk, S.; Antipov, D.; Gurevich, A.A.; Dvorkin, M.; Kulikov, A.S.; Lesin, V.M.; Nikolenko, S.I.; Pham, S.; Prjibelski, A.D.; et al. SPAdes: A New Genome Assembly Algorithm and Its Applications to Single-Cell Sequencing. J. Comput. Biol. 2012, 19, 455-477. [CrossRef] [PubMed]

35. Vallenet, D.; Belda, E.; Calteau, A.; Cruveiller, S.; Engelen, S.; Lajus, A.; Le Fèvre, F.; Longin, C.; Mornico, D.; Roche, D.; et al. MicroScope-an integrated microbial resource for the curation and comparative analysis of genomic and metabolic data. Nucleic Acids Res. 2013, 41, D636-D647. [CrossRef]

36. Aziz, R.K.; Bartels, D.; Best, A.A.; DeJongh, M.; Disz, T.; Edwards, R.A.; Formsma, K.; Gerdes, S.; Glass, E.M.; Kubal, M.; et al. The RAST Server: Rapid Annotations using Subsystems Technology. BMC Genomics 2008, 9, 75. [CrossRef]

37. Taniai, H.; Iida, K.; Seki, M.; Saito, M.; Shiota, S.; Nakayama, H.; Yoshida, S. Concerted Action of Lactate Oxidase and Pyruvate Oxidase in Aerobic Growth of Streptococcus pneumoniae: Role of Lactate as an Energy Source. J. Bacteriol. 2008, 190, 3572-3579. [CrossRef]

38. Streitenberger, S.A.; López-Mas, J.A.; Sánchez-Ferrer, A.; García-Carmona, F. Highly efficient Aerococcus viridans L - $\alpha$-glycerophosphate oxidase production in the presence of $\mathrm{H}_{2} \mathrm{O}_{2}$-decomposing agent: Purification and kinetic characterization. Appl. Microbiol. Biotechnol. 2001, 57, 329-333. [CrossRef]

39. Blin, K.; Wolf, T.; Chevrette, M.G.; Lu, X.; Schwalen, C.J.; Kautsar, S.A.; Suarez Duran, H.G.; de Los Santos, E.L.C.; Kim, H.U.; Nave, M.; et al. antiSMASH 4.0-improvements in chemistry prediction and gene cluster boundary identification. Nucleic Acids Res. 2017, 45, W36-W41. [CrossRef]

40. van Heel, A.J.; de Jong, A.; Song, C.; Viel, J.H.; Kok, J.; Kuipers, O.P. BAGEL4: A user-friendly web server to thoroughly mine RiPPs and bacteriocins. Nucleic Acids Res. 2018, 46, W278-W281. [CrossRef]

41. Carver, T.; Harris, S.R.; Berriman, M.; Parkhill, J.; McQuillan, J.A. Artemis: An integrated platform for visualization and analysis of high-throughput sequence-based experimental data. Bioinformatics 2012, 28, 464-469. [CrossRef] [PubMed]

42. Gabrielsen, C.; Brede, D.A.; Nes, I.F.; Diep, D.B. Circular Bacteriocins: Biosynthesis and Mode of Action. Appl. Environ. Microbiol. 2014, 80, 6854-6862. [CrossRef] [PubMed]

43. Peri, S.; Steen, H.; Pandey, A. GPMAW-A software tool for analyzing proteins and peptides. Trends Biochem. Sci. 2001, 26, 687-689. [CrossRef]

44. Nielsen, H.; Tsirigos, K.D.; Brunak, S.; von Heijne, G. A Brief History of Protein Sorting Prediction. Protein J. 2019, 38, 200-216. [CrossRef]

45. Navarro-Muñoz,J.C.; Selem-Mojica, N.; Mullowney,M.W.; Kautsar,S.A.; Tryon,J.H.; Parkinson, E.I.; De Los Santos, E.L.C.; Yeong, M.; Cruz-Morales, P.; Abubucker, S.; et al. A computational framework to explore large-scale biosynthetic diversity. Nat. Chem. Biol. 2019, 16, 60-68. [CrossRef]

46. Matamoros, S.; Pilet, M.F.; Gigout, F.; Prévost, H.; Leroi, F. Selection and evaluation of seafood-borne psychrotrophic lactic acid bacteria as inhibitors of pathogenic and spoilage bacteria. Food Microbiol. 2009, 26, 638-644. [CrossRef] [PubMed]

47. Fall, P.A.; Leroi, F.; Chevalier, F.; Guérin, C.; Pilet, M.-F. Protective Effect of a Non-Bacteriocinogenic Lactococcus piscium CNCM I-4031 Strain Against Listeria monocytogenes in Sterilized Tropical Cooked Peeled Shrimp. J. Aquat. Food Prod. Technol. 2010, 19, 84-92. [CrossRef]

48. Metivier, A.; Pilet, M.-F.; Dousset, X.; Sorokine, O.; Anglade, P.; Zagorec, M.; Piard, J.-C.; Marlon, D.; Cenatiempo, Y.; Fremaux, C. Divercin V41, a new bacteriocin with two disulphide bonds produced by Carnobacterium divergens V41: Primary structure and genomic organization. Microbiology 1998, 144, 2837-2844. [CrossRef]

49. Wang, K.C.; Ohnuma, S. Isoprenyl diphosphate synthases. Biochim. Biophys. Acta BBA Mol. Cell Biol. Lipids 2000, 1529, 33-48. [CrossRef]

50. Tsuchiya, T.; Takaichi, S.; Misawa, N.; Maoka, T.; Miyashita, H.; Mimuro, M. The cyanobacterium Gloeobacter violaceus PCC 7421 uses bacterial-type phytoene desaturase in carotenoid biosynthesis. FEBS Lett. 2005, 579, 2125-2129. [CrossRef]

51. Gao, P.; Davies, J.; Kao, R. Dehydrosqualene Desaturase as a Novel Target for Anti-Virulence Therapy against Staphylococcus aureus. mBio 2017, 8, e01224-17. [CrossRef] [PubMed] 
52. Challis, G.L.; Naismith, J.H. Structural aspects of non-ribosomal peptide biosynthesis. Curr. Opin. Struct. Biol. 2004, 14, 748-756. [CrossRef] [PubMed]

53. Copp, J.N.; Neilan, B.A. The Phosphopantetheinyl Transferase Superfamily: Phylogenetic Analysis and Functional Implications in Cyanobacteria. Appl. Environ. Microbiol. 2006, 72, 2298-2305. [CrossRef] [PubMed]

54. Tulini, F.L.; Lohans, C.T.; Bordon, K.C.F.; Zheng, J.; Arantes, E.C.; Vederas, J.C.; De Martinis, E.C.P. Purification and characterization of antimicrobial peptides from fish isolate Carnobacterium maltaromaticum C2: Carnobacteriocin X and carnolysins A1 and A2. Int. J. Food Microbiol. 2014, 173, 81-88. [CrossRef] [PubMed]

55. Martin-Visscher, L.A.; van Belkum, M.J.; Garneau-Tsodikova, S.; Whittal, R.M.; Zheng, J.; McMullen, L.M.; Vederas, J.C. Isolation and characterization of carnocyclin a, a novel circular bacteriocin produced by Carnobacterium maltaromaticum UAL307. Appl. Environ. Microbiol. 2008, 74, 4756-4763. [CrossRef] [PubMed]

56. Quadri, L.E.; Sailer, M.; Roy, K.L.; Vederas, J.C.; Stiles, M.E. Chemical and genetic characterization of bacteriocins produced by Carnobacterium piscicola LV17B. J. Biol. Chem. 1994, 269, 12204-12211.

57. Jack, R.W.; Wan, J.; Gordon, J.; Harmark, K.; Davidson, B.E.; Hillier, A.J.; Wettenhall, R.E.; Hickey, M.W.; Coventry, M.J. Characterization of the chemical and antimicrobial properties of piscicolin 126, a bacteriocin produced by Carnobacterium piscicola JG126. Appl. Environ. Microbiol. 1996, 62, 2897-2903. [CrossRef]

58. Acedo, J.Z.; Towle, K.M.; Lohans, C.T.; Miskolzie, M.; McKay, R.T.; Doerksen, T.A.; Vederas, J.C.; Martin-Visscher, L.A. Identification and three-dimensional structure of carnobacteriocin XY, a class IIb bacteriocin produced by Carnobacteria. FEBS Lett. 2017, 591, 1349-1359. [CrossRef]

59. Worobo, R.W.; Van Belkum, M.J.; Sailer, M.; Roy, K.L.; Vederas, J.C.; Stiles, M.E. A signal peptide secretion-dependent bacteriocin from Carnobacterium divergens. J. Bacteriol. 1995, 177, 3143-3149. [CrossRef]

60. Sánchez, J.; Diep, D.B.; Herranz, C.; Nes, I.F.; Cintas, L.M.; Hernández, P.E. Amino acid and nucleotide sequence, adjacent genes, and heterologous expression of hiracin JM79, a sec-dependent bacteriocin produced by Enterococcus hirae DCH5, isolated from Mallard ducks (Anas platyrhynchos). FEMS Microbiol. Lett. 2007, 270, 227-236. [CrossRef]

61. Cui, Y.; Zhang, C.; Wang, Y.; Shi, J.; Zhang, L.; Ding, Z.; Qu, X.; Cui, H. Class Ila Bacteriocins: Diversity and New Developments. Int. J. Mol. Sci. 2012, 13, 16668-16707. [CrossRef] [PubMed]

62. Snauwaert, I.; Hoste, B.; De Bruyne, K.; Peeters, K.; De Vuyst, L.; Willems, A.; Vandamme, P. Carnobacterium iners sp. nov., a psychrophilic, lactic acid-producing bacterium from the littoral zone of an Antarctic pond. Int. J. Syst. Evol. Microbiol. 2013, 63, 1370-1375. [CrossRef] [PubMed]

63. Zhu, S.; Lin, D.; Xiong, S.; Wang, X.; Xue, Z.; Dong, B.; Shen, X.; Ma, X.; Chen, J.; Yang, J. Carnobacterium antarcticum sp. nov., a psychrotolerant, alkaliphilic bacterium isolated from sandy soil in Antarctica. Int. J. Syst. Evol. Microbiol. 2018, 68, 1672-1677. [CrossRef] [PubMed]

64. Bhugaloo-Vial, P.; Dousset, X.; Metivier, A.; Sorokine, O.; Anglade, P.; Boyaval, P.; Marion, D. Purification and amino acid sequences of piscicocins V1a and V1b, two class IIa bacteriocins secreted by Carnobacterium piscicola V1 that display significantly different levels of specific inhibitory activity. Appl. Environ. Microbiol. 1996, 62, 4410-4416. [CrossRef] [PubMed]

65. Miescher, S.; Stierli, M.P.; Teuber, M.; Meile, L. Propionicin SM1, a Bacteriocin from Propionibacterium jensenii DF1: Isolation and Characterization of the Protein and its Gene. Syst. Appl. Microbiol. 2000, 23, 174-184. [CrossRef]

66. Dagan, T. Phylogenomic networks. Trends Microbiol. 2011, 19, 483-491. [CrossRef]

67. Chan, J.Z.-M.; Halachev, M.R.; Loman, N.J.; Constantinidou, C.; Pallen, M.J. Defining bacterial species in the genomic era: Insights from the genus Acinetobacter. BMC Microbiol. 2012, 12, 302. [CrossRef]

68. Wiernasz, N.; Leroi, F.; Chevalier, F.; Cornet, J.; Cardinal, M.; Rohloff, J.; Passerini, D.; Skırnisdóttir, S.; Pilet, M.-F. Salmon Gravlax Biopreservation With Lactic Acid Bacteria: A Polyphasic Approach to Assessing the Impact on Organoleptic Properties, Microbial Ecosystem and Volatilome Composition. Front. Microbiol. 2019, 10, 3103. [CrossRef]

69. Brillet, A.; Pilet, M.-F.; Prevost, H.; Cardinal, M.; Leroi, F. Effect of inoculation of Carnobacterium divergens V41, a biopreservative strain against Listeria monocytogenes risk, on the microbiological, chemical and sensory quality of cold-smoked salmon. Int. J. Food Microbiol. 2005, 104, 309-324. [CrossRef]

70. Spanu, C.; Piras, F.; Mocci, A.M.; Nieddu, G.; De Santis, E.P.L.; Scarano, C. Use of Carnobacterium spp protective culture in MAP packed Ricotta fresca cheese to control Pseudomonas spp. Food Microbiol. 2018, 74, 50-56. [CrossRef] 
71. Marmann, A.; Aly, A.; Lin, W.; Wang, B.; Proksch, P. Co-Cultivation-A Powerful Emerging Tool for Enhancing the Chemical Diversity of Microorganisms. Mar. Drugs 2014, 12, 1043-1065. [CrossRef] [PubMed]

72. Bode, H.B.; Bethe, B.; Höfs, R.; Zeeck, A. Big effects from small changes: Possible ways to explore nature's chemical diversity. ChemBioChem 2002, 3, 619-627. [CrossRef]

73. Holley, R.A.; Guan, T.Y.; Peirson, M.; Yost, C.K. Carnobacterium viridans sp. nov., an alkaliphilic, facultative anaerobe isolated from refrigerated, vacuum-packed bologna sausage. Int. J. Syst. Evol. Microbiol. 2002, 52, 1881-1885. [CrossRef] [PubMed]

(C) 2020 by the authors. Licensee MDPI, Basel, Switzerland. This article is an open access article distributed under the terms and conditions of the Creative Commons Attribution (CC BY) license (http://creativecommons.org/licenses/by/4.0/). 